\title{
Intake of folic acid by Polish women with higher education - a survey research: can we do more?
}

\author{
Malwina Pietrzykowska-Kuncman ${ }^{1}$, Dorota Zasina-Olaszek ${ }^{1}$, Łukasz Kuncman², \\ Marta Niedźwiecka ${ }^{1}$, Krzysztof Szaflik $^{3}$, Iwona Maroszyńska ${ }^{1}$ \\ ${ }^{1}$ Polish Mother's Memorial Hospital Research Institute. Department of Intensive Care and Congenital Malformations \\ of Newborns and Infants, Lodz, Poland \\ ${ }^{2}$ Medical University of Lodz. The Department of Radiotherapy, Lodz, Poland \\ ${ }^{3}$ Polish Mother's Memorial Hospital Research Institute. Department of Gynecology, Fertility and Fetal Therapy, Lodz, Poland
}

\begin{abstract}
Objectives: The objective of the study is to determine efficacy of the Primary Prevention Program of Neural Tube Defects in Polish women with higher education in 5-year interval.

Material and methods: Survey research was conducted twice (in 2008 and 2013) in 630 female students of universities: 305 female medical students and 325 female non-medical students. The survey was also done among women aged 27-35 who graduated from medical or non-medical universities and have at least one child. Questions concerned knowledge about prophylaxis and periconceptional folic acid intake. Chi square test was used to assess the significance.

Results: Knowledge concerning prophylaxis was significantly higher in female medical students comparing to non-medical ones, both in 2008 ( $<<0,001)$, and in $2013(p<0,001) .92 .9 \%$ in 2008 and 93.9\% in 2013 of medical students knew about the necessity of periconceptional folic acid intake. Awareness of female non-medical students was lower ( $2008-35.3 \%$ and $2013-41.1 \%)$ and did not change in the 5 -year long period $(p=0.3)$.

There was no significant difference in preconceptional folic acid intake among mothers with medical and non-medical education ( $53.3 \%$ vs. $45 \%$ p $=0.4)$. However, the highest folic acid intake was among mothers -medical doctors who treat children with neural tube defect.

Conclusions: Difference between medical and non-medical students shows that better educational programs may improve knowledge about prophylaxis. Aside from knowledge, compliance with recommendations of Primary Prevention Program of Neural Tube Defects is unsatisfactory.
\end{abstract}

Key words: congenital abnormalities, folic acid, neural tube defects

Ginekologia Polska 2017; 88, 8: 428-433

\section{INTRODUCTION}

Neural tube defect (NTD) is one of the most common and most severe congenital malformations affecting child development. They present with urination and defecation disorders, paresis and limb paralysis. Hydrocephalus and lower limbs' deformation may often be the consequence of such defect. Due to limited treatment potential, the significance of prophylaxis is high. In 1980 Smithells from Leeds (UK) showed that a supplementary intake of 0.4 [mg] of folic acid before and at the beginning of pregnancy significantly reduces incidence of NTD [1]. This finding was confirmed by numerous clinical studies conducted at large female populations (over 250000 subjects). A multicenter research performed by MRC Vitamin Study Research Group (1991) in 1817 women from 33 countries that had high risk of NTD in a child due to previously affected pregnancy showed that periconceptional folic acid intake reduces occurrence of NTD by $72 \%$ [2].

Similarly, other studies have revealed that the supplementation of folate 4 weeks prior to conception and throughout the first trimester pregnancy is effective in NTD prophylaxis also in women with a negative NTD family history $[3,4]$. 
Seremak-Mrozikiewicz has demonstrated that active form of folate (metafolin) may be efficiently used in NTD prophylaxis in women who are carriers of mutated variants of polymorphic genes for enzymes involved in folate metabolism [5].

Today there is evidence that folic acid supplementation reduces occurrence of some other congenital malformations as well, including heart defects, cleft lip and palate, urinary and gastrointestinal tract malformations [6-8].

Moreover, folic acid intake decreases the risk of obstetric complications such as pre-eclampsia, spontaneous abortion, preterm delivery or delivery of small-for-gestational-age neonate $[9,10]$. A low blood level of folate in pregnant women is associated with increased incidence of neurodevelopmental disorders in children [11, 12]. Meta-analysis by Goh et al. showed that the use of multivitamin preparations with folic acid by pregnant women reduces occurrence of cancer in their children (leukemia, brain cancer and neuroblastoma) [13].

In 1997 Polish Gynecological Society introduced Primary Prevention Program of Neural Tube Defects that involves supplementation of folic acid. The aim of this project is to popularize intake of $0.4[\mathrm{mg}]$ of folic acid by all women who may potentially become pregnant and to spread knowledge about primary prophylaxis of NTD in the society. According to the Polish Gynecological Society Expert Group (2011) the supplementation should be started at least 6 weeks before planned conception and should be continued until the second trimester of pregnancy [14].

\section{OBJECTIVES}

The objective of this paper is to determine the efficacy of the Primary Prevention Program of NTDs in women with higher education in Łódź- the third largest city in Poland (with regard to population). The survey research was conducted twice: in 2008 and in 2013.

\section{MATERIAL AND METHODS}

The survey was conducted in Łódź - the third largest city in Poland (with regard to population). From a total of 22 higher education institutions ( 6 public and 16 non-public) in the city we selected 3 biggest institutions, namely: Medical University of Łódź, Technical University of Łódź and University of Łódź.

The research included the following groups of women: 630 female medical and non-medical students, 120 young women with higher education who have at least one child and 81 mothers of neonates born with NTD.

\section{Female students of medical and non-medical faculties}

The survey among a total of 630 medical and non-medical students was conducted twice: in 2008 and in 2013. Subjects were divided into two groups. The first group (305 women) comprised female medical students (faculties of medicine, dentistry and pharmacy of Medical University of Łódź). The second group (325 women) comprised female non-medical students (faculties of civil engineering, architecture and environmental engineering of Technical University of Łódź and faculties of economics and sociology of University of Łódź). The survey was conducted at the end of lectures and random sampling selected every third student.

Answers were collected personally with a direct interview by investigators educated in the field of pediatrics and neonatology. To minimize the interviewer bias, three interviewers were involved and used unified rules of asking questions and interpreting the answers. Students were asked about primary prophylaxis of NTDs. The answer was considered correct when the student recognized that primary prophylaxis of NTDs involves periconceptional intake of folic acid, regardless of its form.

\section{Women with medical and non-medical higher education who have at least one child}

The study included also females aged 27-35 that are mothers to at least one child and who graduated from one of the universities in Łódź. A group of 60 mothers were graduates of Medical University of Łódź and worked as medical doctors (residents) in the Polish Mother's Memorial Hospital Research Institute in Łódź. They were interviewed at the end of lectures for residents (obligatory classes during the training program in pediatrics, neonatology, gynecology and obstetrics, not related to folic acid topic). Another group of 60 mothers were graduates of Technical University of Łódź and the University of Łódź and they were interviewed at kindergartens in Łódź. Every third mother with an adequate education was selected by random sampling for the survey. All mothers (with medical or non-medical higher education) were asked personally if they had taken folic acid 6 weeks before conception and during the pregnancy. Women who were not sure about timing of their folic acid supplementation were excluded from the study.

The group of mothers with medical higher education included female doctors $(n=9)$ who worked at the Department of Intensive Care and Congenital Malformations of Newborns and Infants where neonates with NTDs are treated. They were asked if they had taken folic acid 6 weeks before conception and during the pregnancy. They were also asked if their pregnancy had started before or after they began working at the department.

\section{Mothers of neonates born with the NTD}

Finally, the last group included in the survey was that of 81 mothers of neonates with NTD that were treated between 2004 and 2015 at the Department of Intensive Care 
and Congenital Malformations of Newborns and Infants of the Polish Mother's Memorial Hospital Research Institute (the only treatment center of NTDs in Łódź province). The respondents were divided into two groups: mothers of neonates born between 2004-2009 ( $n=50)$ and mothers of neonates born between 2010-2015 ( $n=31)$. An investigator conducted the survey personally or by phone.

Statistical calculations were performed using Statistica (version 12) software of Stat Soft. A chi-square test was used. The results were regarded as statistically significant if $\mathrm{p}<0.05$.

All data was collected with the approval of the Institutional Review Board of the Polish Mother's Memorial Hospital Research Institute in Łódź in Poland.

\section{RESULTS}

\section{Female students of medical and non-medical faculties}

The analysis of the survey has showed that in the year 2008 the knowledge about NTD prophylaxis was significantly more common in the group of female medical students compared to non-medical ones $(92.1 \%$ vs. $38 \% p<0,001)$ (Figure 1). Compared to repeated survey 5 years later in 2013 , the awareness of medical students remained significantly higher than non-medical students ( $93.3 \%$ vs. $57.1 \%$ $\mathrm{p}<0,001)$. Also, the level of knowledge did not change significantly over the 5 years interval (2008-2013) between medical $(p=0.7)$ and non-medical $(p=0.3)$ students.

\section{Women with medical and non-medical higher education who have at least one child}

The analysis of the survey has showed that folic acid prior to conception was supplemented by only $53.3 \%$ of mothers that graduated from medical faculties compared to $45 \%$ of mothers that graduated from non-medical faculties (Figure 2). However, the difference between the two groups is not statistically significant $(p=0.4)$. During pregnancy in turn $100 \%$ of mothers with medical education supplemented folic acid compared to $83.3 \%$ of mothers with non-medical education. This difference is statistically significant $(p<0,001)$.

The group of mothers with medical education includes female doctors who worked in the center of NTDs treatment. If the pregnancy started after the female doctors had begun to work in the center, folic acid was supplemented in all cases with no exception. In turn, if the pregnancy started before the employment at the center, only $37.5 \%$ of pregnancies were preceded by folic acid intake.

\section{Mothers of neonates born with the NTD}

The proportion of mothers that supplemented folic acid prior the conception and gave birth to a neonate with

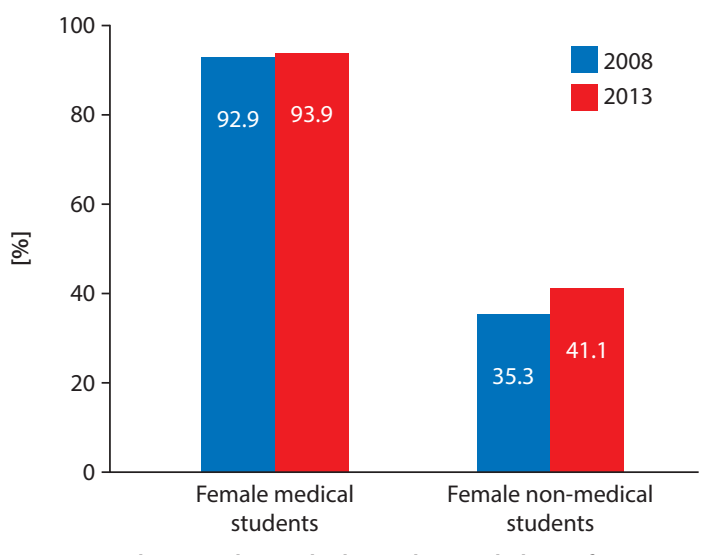

Figure 1. Level of knowledge concerning prophylaxis of NTDs in female students

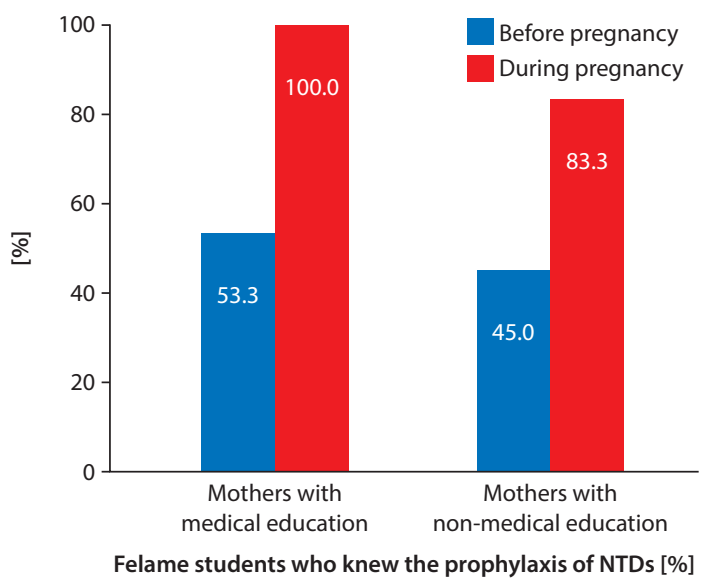

Figure 2. Supplementation of folic acid in a group of mothers with medical and non-medical education

NTD treated at Polish Mother's Memorial Hospital Research Institute in Łódź between 2004-2009 and between 20102015 was $26 \%$ and $45.2 \%$, respectively (Table 1 ). Yet, the difference between the groups in time is not statistically significant ( $p=0.07$ ). Folacin was supplemented during pregnancy by $92 \%$ of mothers who gave birth to a child with NTD in 2004-2009 and $96.8 \%$ in 2010-2015. The time difference is not statistically significant either $(p=0.38)$.

\section{DISCUSSION}

Our results indicate that less than a half of female non-medical students of universities in Łódź know about the need of periconceptional folic acid intake. This situation did not change across the years 2008-2013. In contrast, awareness of NTDs prophylaxis in female medical students is high. However, only more than half of mothers with medical education used folacin before pregnancy. It is worth mentioning that this group includes medical doc- 
Table 1. Folic acid supplementation in mothers of children with the NTD and additional information from questionnaire

\begin{tabular}{|l|c|c|c|}
\hline & $\begin{array}{c}\text { Mothers of children with the NTD } \\
\text { born between } \mathbf{2 0 0 4} \text { and 2009 }\end{array}$ & $\begin{array}{c}\text { Mothers of children with the NTD } \\
\text { born between } 2010 \text { and } 2015\end{array}$ \\
\hline Number & 50 & 31 \\
\hline Folic acid at least 6 weeks before conception & $13(26 \%)$ & $14(45.2 \%)$ \\
\hline Folic acid during pregnancy & $46(92 \%)$ & $30(96.8 \%)$ \\
\hline $\begin{array}{l}\text { Informed by a gynaecologist about need of folic } \\
\text { acid supplementation }\end{array}$ & $22(44 \%)$ & $24(77.4 \%)$ \\
\hline Prenatal tests during pregnancy & $31(62 \%)$ & $31(100 \%)$ \\
\hline Smoking during pregnancy & $13(26 \%)$ & $1(3.2 \%)$ \\
\hline Alcohol intake during pregnancy & $4(8 \%)$ & 0.38 \\
\hline Infection during pregnancy & $11(22 \%)$ & 0.003 \\
\hline
\end{tabular}

tors that are residents in pediatrics, neonatology, gynecology and obstetrics. There were no significant differences with regard to NTDs prophylaxis prior to pregnancy onset between groups of women that graduated from medical compared to non-medical faculties of universities in Łódź. Pre-conceptional folic acid intake was similar in both medical and non-medical education groups. Yet, even though many women know about the need of periconceptional folic acid intake, they do not always supplement it before the conception. A possible cause for this may be the high percentage of unplanned pregnancies in Poland. A study of Woude et al. showed that periconceptional folic acid supplementation during the recommended period was used significantly more often by women who planned pregnancy [15]. Low compliance with periconceptional folic acid intake recommendations may also be associated with inadequate knowledge of young women about the character and the complications of NTDs. It is worth mentioning that $100 \%$ of female medical doctors who dealt with children with NTD in their practice supplemented folic acid prior to conception.

According to a European study of Fulford et al., only $45.5 \%$ of 651 young women from Poland, France, Belgium and Germany who planned pregnancy or who were at the early stage of the pregnancy implemented NTDs prophylaxis despite the fact that $82.8 \%$ of them had known about such recommendations [16]. Bitzer et al. revealed that $70 \%$ of respondents to his survey (22925 women of reproductive age from 18 European countries) have heard about folic acid but only $7 \%$ of all women, $28 \%$ of women planning pregnancy and $55 \%$ of pregnant women used folacin [17]. Also, the percentage of women who knew what the prophylaxis of folic acid is used for was very low (17\%). The results of other surveys conducted in European countries show similar results. According to a Danish project only $10.4 \%$ of women complied with the recommendations of periconceptional prophylaxis, while for Ireland and Spain the proportion is $24.7 \%$ and $19.2 \%$, respectively [18-20]. Reports of EUROCAT $(2009,2013)$ showed that the supplementation of folic acid in the recommended period before planned pregnancy was used by more than $40 \%$ of women only in Holland, Norway and United Kingdom. Other countries had considerably lower rates [21-22].

Only a few studies describe the education level of Polish women with regard to NTDs prophylaxis. According to Bagłaj and Wojtyłko, only $17.8 \%$ of 894 mothers of neonates hospitalized at the Department of Pediatric Surgery and Urology between 2001 and 2010 had used folic acid before the pregnancy [23]. Only $35.8 \%$ of mothers in 2010 and $7.1 \%$ of mothers in 2001 complied with recommendations of NTDs prophylaxis. Women with higher education supplement folate most often (37.8\%). Twenty-eight percent of mothers did not supplement folic acid despite their adequate knowledge about it. Among mothers of children with NTD, only $13.5 \%$ supplemented folacin in the preconceptional period. By comparison, our study reports that $26 \%$ of women who gave birth to a child with NTD in the similar period of time, supplemented folic acid before pregnancy. We observed no significant difference in folic acid use before and during the pregnancy in the groups of mothers of NTD neonates born between 2004-2009 and between 2010-2015.

The review of the literature together with this paper shows that the number of young women who supplement folic acid is unsatisfactory. Some women do not comply with the NTDs prophylaxis because they do not know the principles of it. However, a significant proportion of women in reproductive age do not supplement folic acid despite their knowledge. The reason for this may be inadequate awareness about quality of life of patients with NTDs. It is probably an important factor behind the inadequate efficacy of programs promoting prophylaxis of NTDs in many countries around the world. According to reports of EUROCAT (2009 and 2013), the projects conducted by countries of the European Union fell short of expectations [21, 22]. The majority of countries included in the study recorded no satisfactory decrease in incidence of NTDs. Although a decrease of live births of neonates with such defects was 
observed, it was associated with better prenatal diagnostics and termination of pregnancies rather than with effective primary prophylaxis.

Obeid et al. went a step further and called the occurrence of NTDs in Europe an epidemy, since it is 1.6 fold higher compared to countries that fortify food with folic acid [24]. The authors concluded that high prevalence (7478 out of approximately 9 million births) of pregnancies with NTDs between years 2000-2010 was caused by a failure of European governments to introduce folic acid fortification on a population level.

In the United States recommendations concerning periconceptional folic acid intake were implemented in 1992 [25]. However, a research survey conducted by Center for Disease Control and Prevention (1999) showed that only $25 \%$ of women in reproductive age took folacin [26]. Implementation of food fortification with folic acid in 1998 in USA and Canada caused a significant decrease of NTDs. The incidence of spina bifida decreased by $31 \%$ and $53 \%$ in the USA and Canada, respectively $[27,28]$. A study conducted by lonescu-Ittu et al. showed a significant drop in incidence of congenital heart defects in Quebec province in Canada after implementation of mandatory food fortification [29]. Recently, according to the Food Fortification Initiative, such program is being conducted in 79 countries. (http://www.ffinetwork.org/)

Obligatory food fortification with folic acid was not implemented in Europe due to concerns about adverse effects in the whole society. Uncontrolled use of folacin in high doses may increase the incidence of cancer of large intestine, prostate or breast and mask the symptoms of pernicious anemia in elderly people [30-32]. However, the experience of different European countries and ours indicate that the efficacy of implemented educational programs is unsatisfactory and more effort needs to be undertaken to improve the compliance with periconceptional folic acid intake.

For the purpose of this survey we have intentionally selected women with higher education since several studies revealed that such population is most compliant with recommendation of folacin supplementation [15, 33]. This data suggests that efficacy of the folic acid education campaign in women without university education can be even less satisfactory.

The possible limitation of our study is the interviewer bias. To minimize it the interviewers used the unified rules of asking questions and interpreting the answers. In order to avoid selection bias, random sampling was used.

In summary, compliance with Polish Primary Prevention Program of NTDs is unsatisfactory. Only among medical students knowledge about the need of periconceptional folic acid supplementation is adequate. However, this knowledge and the compliance with recommendations do not match. Only over a half of mothers with medical education used folacin before pregnancy despite their adequate knowledge. Folic acid intake was satisfactory in a group of medical doctors working in the NTDs treatment center only. Our observation is that $100 \%$ of pregnancies were preceded by folic acid intake when the pregnancy started after the employment in the NTDs treatment center, which compares to only $37.5 \%$ when pregnancy started before the contact with children with NTD. Thus, when abandoning the idea of food fortification with folic acid, implementation of better educational programs with more complete information about NTDs and the quality of life of children with NTDs should also be considered.

\section{CONCLUSIONS}

1. The research survey indicates that the efficacy of education program concerning NTDs prophylaxis in Poland is unsatisfactory. Even in the group of female medical doctors periconceptional folic acid intake was low. Only in the group of female doctors who worked in the center of NTDs treatment, folic acid supplementation prior to conception was at satisfactory level.

2. Compliance with folic acid recommendations may be improved by introducing not only the education about the prevention of birth defects but also the awareness of their consequences in future life.

3. Mandatory food fortification with folic acid, like in other countries in the world, is still an open issue.

\section{REFERENCES}

1. Smithells RW, Nevin NC, Seller MJ, et al. Further experience of vitamin supplementation for prevention of neural tube defect recurrences. Lancet Lond Engl. 1983; 1: 1027-1031, doi: 10.1016/s0140-6736(83)92654-5, indexed in Pubmed: 6133069.

2. MRC Vitamin Study Research Group. Prevention of neural tube defects: results of the Medical Research Council Vitamin Study. MRC Vitamin Study Research Group. Lancet. 1991; 338: 131-137, doi: 10.1016/01406736(91)90133-a, indexed in Pubmed: 1677062.

3. Czeizel AE, Dudás I. Prevention of the first occurrence of neural-tube defects by periconceptional vitamin supplementation. N Engl J Med. 1992; 327: 1832-1835, doi: 10.1056/NEJM199212243272602, indexed in Pubmed: 1307234.

4. Berry RJ, Li Z, Erickson JD, et al. Prevention of Neural-Tube Defects with Folic Acid in China. N Engl J Med. 1999; 341: 1485-1490, doi: 10.1056/nejm199912093412424.

5. Seremak-Mrozikiewicz A. Metafolin - alternative for folate deficiency supplementation in pregnant women. Ginekol Pol. 2013; 84: 641-646, doi: 10.17772/gp/1618, indexed in Pubmed: 24032278.

6. Czeizel AE. Periconceptional folic acid and multivitamin supplementation for the prevention of neural tube defects and other congenital abnormalities. Birt Defects Res A Clin Mol Terato. 2009; 85: 260-268, doi: 10.1002/bdra.20563.

7. Goh YI, Koren G. Folic acid in pregnancy and fetal outcomes. J Obstet Gynaecol J Inst Obstet Gynaecol. 2008; 28: 3-13, doi: 10.1080/01443610701814195, indexed in Pubmed: 18259891.

8. Yazdy MM, Honein MA, Xing J. Reduction in orofacial clefts following folic acid fortification of the U.S. grain supply. Birt Defects Res A Clin Mol Teratol. 2007; 79: 16-23, doi: 10.1002/bdra.20319, indexed in Pubmed: 17177274

9. Fekete K, Berti C, Cetin I, et al. Perinatal folate supply: relevance in health outcome parameters. Matern Child Nutr. 2010; 6: 23-38, doi: 10.1111/j.1740-8709.2010.00261.x, indexed in Pubmed: 22296249.

10. Hodgetts VA, Morris RK, Francis A, et al. Effectiveness of folic acid supplementation in pregnancy on reducing the risk of small-for-gestational age neonates: a population study, systematic review and meta-analy- 
sis. BJOG Int J Obstet Gynaeco. 2015; 122: 478-490, doi: 10.1111/14710528.13202, indexed in Pubmed: 25424556.

11. Roza SJ, van Batenburg-Eddes T, Steegers EAP, et al. Maternal folic acid supplement use in early pregnancy and child behavioural problems: The Generation R Study. Br J Nutr. 2010; 103: 445-452, doi: 10.1017/S0007114509991954, indexed in Pubmed: 19772683.

12. Steenweg-de Graaff J, Roza SJ, Steegers EAp, et al. Maternal folate status in early pregnancy and child emotional and behavioral problems: the Generation R Study. Am J Clin Nutr. 2012; 95: 1413-1421, doi: 10.3945/ajcn.111.030791, indexed in Pubmed: 22572645.

13. Goh YI, Bollano E, Einarson TR, et al. Prenatal multivitamin supplementation and rates of pediatric cancers: a meta-analysis. Clin Pharmacol Ther. 2007; 81: 685-691, doi: 10.1038/sj.clpt.6100100, indexed in Pubmed: 17314929.

14. Polish Gynecological Society Expert Group. Expert review of Polish Gynecological Society regarding micronutrient supplementation in pregnancy. Ginekol Pol. 2011; 82: 550-3.

15. Der Woude PAZ, Walle HE, Berg LTV, et al. Periconceptional folic acid use: still room to improve. Birth Defects Res A Clin Mol Teratol. 2012; 94: 96-101, doi: 10.1002/bdra.22882, indexed in Pubmed: 22246989.

16. Fulford B, Macklon N, Boivin J, et al. Mental models of pregnancy may explain low adherence to folic acid supplementation guidelines: a cross-sectional international survey. Eur J Obstet Gynecol Reprod Biol. 2014; 176: 99-103, doi: 10.1016/j.ejogrb.2014.02.011, indexed in Pubmed: 24630297.

17. Bitzer J, von Stenglin A, Bannemerschult R, et al. Women's awareness and periconceptional use of folic acid: data from a large European survey. Int JWomens Health. 2013; 5: 201-213, doi: 10.2147/IJWH.S40149, indexed in Pubmed: 23658501.

18. Friberg AK, Jørgensen FS, Friberg AK, et al. Few Danish pregnant women follow guidelines on periconceptional use of folic acid. Dan Med J. 2015; 61 .

19. Cawley S, Mullaney L, McKeating A, et al. An analysis of folic acid supplementation in women presenting for antenatal care. J Public Health Oxf Engl. 2015; 38: 122-129, doi: 10.1093/pubmed/fdv019.

20. Navarrete-Muñoz EM, Giménez Monzó D, García de La Hera M, et al. Folic acid intake from diet and supplements in a population of pregnant women in Valencia, Spain. Med Clínica. 2010; 135: 637-643, doi: 10.1016/j. medcli.2010.03.033, indexed in Pubmed: 21070911.

21. Eurocat. Special Report 2009: Prevention of Neural Tube Defects by Periconceptional Folic Acid Supplementation in Europe. http://eurocat-network.eu/content/Special-Report-NTD-3rdEd-2009.pdf (2009).
22. Eurocat. Eurocat Special Report 2013: Primary Prevention of Congenital Anomalies in European Countries. http://www.eurocat-network.eu/content/Special-Report-Primary-Preventions-of-CA.pdf (2013).

23. Bagłaj $M$, Wojtyłko A, Bagłaj $M$, et al. Folic acid supplementation as prophylaxis of neural tube defect in the Lower Silesia region: fact or fiction? Med Wieku Rozwoj. 2011; 15: 5016.

24. Obeid R, Pietrzik K, Oakley GP, et al. Preventable spina bifida and anencephaly in Europe. Birt Defects Res A Clin Mol Teratol. 2015; 103: 763-771, doi: 10.1002/bdra.23400, indexed in Pubmed: 26178749.

25. Recommendations for the use of folic acid to reduce the number of cases of spina bifida and other neural tube defects. MMWR Recomm Rep Morb Mortal Wkly Rep Recomm Rep Cent Dis Control. 1992; 41: 1-7, indexed in Pubmed: 1522835.

26. Centers for Disease Control and Prevention (CDC). Knowledge and use of folic acid by women of childbearing age--United States, 1995 and 1998. MMWR Morb Mortal Wkly Rep. 1999; 48: 325-327, doi: 10.1001/jama.281.20.1883, indexed in Pubmed: 10366139.

27. Williams $L J$, Mai $C T$, Edmonds LD, et al. Prevalence of spina bifida and anencephaly during the transition to mandatory folic acid fortification in the United States. Teratology. 2002; 66: 33-39, doi: 10.1002/tera.10060, indexed in Pubmed: 12115778.

28. De Wals $\mathrm{P}$, Tairou F, Van Allen Ml, et al. Reduction in neural-tube defects after folic acid fortification in Canada. N Engl J Med. 2007; 357: 135-142, doi: 10.1056/NEJMoa067103, indexed in Pubmed: 17625125.

29. Ionescu-Ittu R, Marelli AJ, Mackie AS, et al. Prevalence of severe congenital heart disease after folic acid fortification of grain products: time trend analysis in Quebec, Canada. BMJ. 2009; 338, doi: 10.1136/bmj. b1673, indexed in Pubmed: 19436079.

30. Kim Yl. Will mandatory folic acid fortification prevent or promote cancer? Am J Clin Nutr. 2004; 80: 1123-8.

31. Kim YI. Does a high folate intake increase the risk of breast cancer? Nutr Rev. 2006; 64: 468-475, doi: 10.1111/j.1753-4887.2006.tb00178.x, indexed in Pubmed: 17063929.

32. Institute of Medicine (US) Standing Committee on the Scientific Evaluation of Dietary Reference Intakes and its Panel on Folate, Other B Vitamins, and Choline. Dietary Reference Intakes for Thiamin, Riboflavin, Niacin, Vitamin B6, Folate, Vitamin B12, Pantothenic Acid, Biotin, and Choline. Washington, 1998.

33. Khodr ZG, Lupo PJ, Agopian AJ, et al. Preconceptional folic acid-containing supplement use in the National Birth Defects Prevention Study. Birt Defects Res A Clin Mol Teratol. 2014; 100: 472-482, doi: 10.1002/bdra.23238, indexed in Pubmed: 24706436. 